\title{
PENYUSUTAN KARENA PENGUAPAN (EVAPORATION LOSS) PADA TANKI JENIS FLOATING ROOF TANK
}

\author{
EVAPORATION LOSS IN FLOATING ROOF TANK TYPES
}

\author{
Indah Agus Setiorini ${ }^{1)}$, Achmad Faisal Faputri ${ }^{2)}$ \\ ${ }^{1,2)}$ Program Studi Teknik Pengolahan Migas Politeknik Akamigas Palembang, 30257, Indonesia \\ Corresponding Author E-mail: indah@pap.ac.id danachmadfaisal@pap.ac.id
}

\begin{abstract}
The amount of losses is strongly influenced by several factors, including ullage (empty space of a storage tank). The higher the ullage, the greater the losses that occur. Losses are also influenced by environmental conditions such as temperature, where high temperatures tend to evaporate light fractions. In storage tanks, the safety factor is an important consideration, one of which is facilities such as Vent and PV Valve as a breathing apparatus in the oil product storage system. Because the "Wind Speed" around the storage tank is the triggering factor for Losses. In addition, losses in storage tanks are also strongly influenced by the physical characteristics of the oil product itself, especially Vapor Pressure (RVP-Reid Vapor Pressure). Evaporation loss it self must be considered because it has an impact on losses in both quantity and quality of an oil product. Basically evaporation loss / loss due to evaporation cannot be avoided, but can be controlled and minimized with adequate facilities, good maintenance, operation and supervision techniques. As an illustration, an example of calculating losses of $131.6 \mathrm{bbl} / \mathrm{year}$ for floating roof tank is presented.
\end{abstract}

Keywords: Evaporation, Losses, Floating Roof Tank

\begin{abstract}
Abstrak: Besarnya losses sangat dipengaruhi oleh beberapa faktor antara lain ullage (ruang kosong suatu storage tank). Semakin tinggi ullage akan semakin besar losses yang terjadi.Losses juga dipengaruhi oleh kondisi lingkungan seperti halnya temperatur, dimana suhu yang tinggi kecenderungan fraksi ringan akan menguap. Dalam storage tank faktor safety menjadi pertimbangan penting salah satunya fasilitas seperti Vent dan PV Valve sebagai alat pernapasan dalam sistem penyimpanan produk minyak wajib tersedia. Karena "Kecepatan Angin" sekitar tanki penyimpanan menjadi faktor pemicu terjadinya Losses. Disamping itu Losses dalam storage tank juga sangat dipengaruhi oleh karakteristik/sifat fisis produk minyak itu sendiri terutama Vapour Pressure (RVP-Reid Vapour Pressure). Evaporation Loss itu sendiri harus diperhatikan karena berdampak pada kerugian baik kuantitas maupun kualitas suatu produk minyak. Pada dasarnya evaporation loss/kehilangan akibat penguapan tidak dapat dihindari, namun dapat dikendalikan dan di minimais dengan fasilitas yang memadai, Teknik pemeliharaan, pengoperasianserta pengawasan yang baik. Sebagai gambaran, disajikan contoh perhitungan Losses sebesar 131,6 bbl/year untuk floating roof tank.

Kata kunci : Penguapan, Kehilangan, Atap Bergerak.
\end{abstract}

\section{PENDAHULUAN}

Pada industri perminyakan losses sangat merugikan. Pada umumnya losses ini tidak saja dipandang merugikan hanya dari segi kuantitas, tetapi juga dari segi kwalitas. Sebab tidak jarang dengan adanya losses, mutu produk berubah dan memburuk. Misalnya saja losses karena penguapan suatu fraksi (white product) akan mengakibatkan kenaikan IBP dan memperbesar spesific gravity, serta merubah sifat distilasinya. Sifat yang memburuk tersebut akan mempengaruhi penggunaan bahan tersebut. Sebagai contoh misalnya losses sebanyak 1,2 \% dari avigas akan mengakibatkan hal-hal sebagai berikut:

a. Spesific gravity naik sebanyak 0,002, misal 0,7664 menjadi 0,7684 . b. IBP naik $3{ }^{\circ} \mathrm{C}$, misal IBP $40^{\circ} \mathrm{C}$ menjadi $43^{\circ} \mathrm{C}$.

c. Temperatur recovery $10 \%$ naik $2{ }^{\circ} \mathrm{C}$, misal $75^{\circ} \mathrm{C}$ menjadi $77^{\circ} \mathrm{C}$.

d. Vapour pressure turun $20 \%$, misal RVP 7,5 psia menjadi 6,0 psia.

e. Octan number turun 0,5 satuan, misal ON 88 menjadi 87,5

Losses dalam perminyakan dapat terjadi mulai field sampai pada konsumen. Losses dalam exsploitasi, transport, pengolahan, distribusi, dan lain-lain. Disamping itu, mungkin juga terjadi losses pada pemakai yang disebabkan oleh karena kesalahan penyimpanan dan penggunaan yang tidak rasionil. Semua ini merugikan dan perlu sekali dicegah. Untuk dapat melakukan pencegahan, tentu harus mengerti sebab-sebab timbulnya losses. Losses dapat terjadi karena 
penguapan, bocoran dan rembesan, kerusakan alat-alat, kontaminasi, dan lain-lain.

Dari hal-hal tersebut diatas, losses dapat diklasifikasikan sebagai berikut :

a. Losses kualitas, yang bersangkutan dengan mutu.

b. Losses kuantitas, yang bersangkutan dengan jumlah.

Losses kuantitas dapat disebabkan karena keadaan tehnis alat-alat yang tidak memenuhi syarat, pipa-pipa dan armaturnya yang tidak baik juga dapat diakibatkan oleh pekerjaan revisi / reparasi atau pemasangan yang kurang sempurna. Banyak hal yang menentukan besar kecilnya losses adalah kecakapan serta keterampilan manusia yang mengangani transport dan penyimpangan.

Kadang-kadang tetesan-tetesan yang terjadi pada sambungan atau equipment dianggap kecil, tetapi kalau dihitung benarbenar akhirnya memberi angka yang cukup besar. Misalnya bila satu detik tetes kecil, maka dalam tempo satu bulan dapat terjadi losses sebanyak kurang lebih 130 - 200 liter.

\section{TEORI DASAR}

\subsection{Sumber Losses}

a. Pada transport

1. Transport dengan pipa

Kebanyakan kehilangan terjadi pada sentral perpompaan dan sambungan-sambungan pipa, armatur (valves, kompensator, flanges, dsb). Dalam sentral pepompaan losses karena kebocoran pompa-pompa karena packing yang kurang baik. Losses juga dapat terjadi pada pencucian pipa transporter.

\section{Transport dengan tank car}

Losses terjadi pada saat pengisian dan pembongkaran. Losses oleh karena alat-alat yang kurang kompak, dan juga sambungansambungan yang tidak baik. Bila penutupan tidak sempurna, dapat juga terjadi penguapan. Losses juga terjadi pada saat diadakan pembersihan atau cleaning.

\section{Transport dengan $K A$}

Losses banyak terjadi pada penuangan (discharge) dan pengisian (loading). Selain itu, dapat terjadi akibat rembesan-rembesan karena sambungan-sambungan atau armatur yang kurang kompak. Adanya sisa-sisa dalam tank setelah discharge (terutama untuk produk berat), dan pencucian tank juga menimbulkan losses.

4. Transport melalui laut

Losses banyak terjadi pada discharge dan loading. Dapat juga pada pernapasan melalui katup pernapasan (breather valve). Losses juga dapat terjadi akibat kurang kompaknya packing pada pompa, sambungan-sambungan pipa, armatur dan sebagainya. Pada pergantian perpompaan jenis produk juga menimbulkan losses kualitatif dan kadang-kadang kwantitatifkuantitatif demikian juga pada saat tank cleaning.

a. Pada penyimpanan

Pada penyimpanan petroleum product, dalam tank dan resorvoir, losses bisa terjadi karena :

1. Pengelasan yang kurang baik dari dinding tanki atau atap (roof).

2. Armatur yang kurang baik (valve, flange, kran dsb).

3. Terbawa air yang didrain dan pada tank cleaning.

4. Pernapasan lewat katup pernapasan (breather valve).

Bila ada perpompaan yang berhubungan dengan tank tersebut, kemungkinan losses terjadi pula pada armatur dan sambungan-sambungan pipa, packing yang kurang sempurna pada sumbu-sumbu pompa.

\subsection{Oil Losses Karena Penguapan}

Oil losses terbesar dalam transport, penyimpanan dan penggunaan product disebabkan oleh penguapan (apalagi bagi product ringan). Faktor-faktor yang mempengaruhi besar kecilnya losses karena penguapan ini, antara lain :

1. Sifat produk antara lain mudah atau sulit menguap ini dapat dilihat dari vapour pressure-nya. Makin besar vapour pressure untuk temperatur yang sama, makin mudah produk tersebut menguap.

2. Cara penyimpanan

3. Konstruksi alat penyimpanan dan kondisi penyimpanan. 
Cara dan kondisi penyimpanan yang berbeda-beda tergantung pada iklim, keadaan meterologi ukuran tank dan penuh tidaknya isi tanki. Dalam tanki, penguapan terjadi bila ruangan di atas liquid belum jenuh terhadap uap liquid tersebut, yaitu tekanan partial uap liquid tersebut dalam rongga diatas permukaan liquid masih lebih kecil dari vapour pressurenya. Penyebaran uap dari liquid tersebut keseluruh ruangan disebabkan adanya difusi dan arus konveksi (two phase convection). Arus konveksi ini terjadi akibat adanya perbedaan temperatur produk dalam tanki selama penyimpanan, yang disebabkan perbedaan temperatur udara dari luar.

Di atas permukaan liquid terdapat lapisan difusi perbatasan antara dua fase. Perpindahan uap dalam lapisan ini karena difusi. Diluar lapisan ini terjadi konveksi yang menyebabkan konsentrasi uap menjadi sama diseluruh ruangan diatas permukaan liquid.

Untuk menghindari timbulnya defermasi dinding tanki, maka dibuatlah sistem pernapasan dengan memasang katup. Bila tekanan membesar akibat pengembangan termis, maka katup tersebut membuka dan mengeluarkan sebagian gas dari ruangan di atas liquid. Sebaliknya bila tekanan mengecil karena penurunan temperatur, maka sebagian udara masuk melewati valves tersebut. Disebabkan adanya perbedaan temperatur siang dan malam, terjadilah penganginan produk dan sebagian produk keluar atmosfir.

Bila man hole terbuka, penguapan membesar. Di daerah dingin pembukaan man hole selama satu bulan untuk tank kapasitas 5 ribu ton, akan terjadi losses sebesar 53 ton untuk produk dan 28 ton untuk crude oil. Akibat pernapasan tersebut, terjadi losses. Pada siang hari terjadi penghembusan gas dari ruangan di atas liquid ke udara dan malam hari terjadi pengisapan udara dari luar ke dalam ruangan tersebut.

Losses akibat pernapasan tersebut, dapat dihitung dengan tepat. Tetapi losses akibat bocor, rembes, dan lain-lain sulit untuk dirumuskan. Losses akibat pernapasan tergantung pada temperatur tanki, tekanan dan berat molekul vapour hidrokarbon.
Untuk gasoline, dalam tanki dengan kapasitas $5.000 \mathrm{~m}^{3}$ dan pengisian $90 \%$ (vapour pressure $400 \mathrm{mmHg}$ ) selama satu hari akan hilang $40 \mathrm{~kg}$ bila pengisian $10 \%$ losses akan naik menjadi $300 \mathrm{~kg}$. Dalam pengisian bensin ke dalam tanki dengan kapasitas $5.000 \mathrm{~m}^{3}$ dari ruangan di atas liquid, akan keluar gas. Gas tersebut merupakan campuran antara uap bensin dan udara, dimana terdapat kurang lebih 4 ton bensin. Makin pendek periode antara pengisian dan pengosongan makin kecil losses. Sebab gas yang keluar tidak begitu jenuh dengan uap bensin. Untuk menghitung jumlah losses pada pernapasan diperlukan data-data meteologi seperti, temperatur, tekanan udara, intensivitas radiasi cahaya matahari, keadaan mendung dan kekuatan angin.

Data tersebut diperlukan untuk perhitungan termodinamika. Hasil perhitungan ini adalah jumlah losses akibat penguapan pada perpompaan dari tanki (discharge) dapat dituliskan sebagai berikut:

$$
\Delta \mathrm{G}=\frac{\mathrm{P}_{\mathrm{par}}}{\mathrm{R}_{\text {vap }} \mathrm{T}} \mathrm{V}
$$

Dimana: $\mathrm{V}=$ volume tanki darimana produk dipompakan $\left(\mathrm{m}^{3}\right)$

$\mathrm{P}_{\mathrm{par}}=$ tekanan vertial produk dalam tanki $\left(\mathrm{kg} / \mathrm{m}^{2}\right)$

$$
\mathrm{P}_{\mathrm{par}}=\mathrm{P}_{\mathrm{s}} \frac{\mathrm{y}}{\mathrm{y}+1}
$$

$\mathrm{P}_{\mathrm{s}}=$ vapour pressure uap produk (tekanan uap jenuh)

$\mathrm{y}=$ parameter yang ditentukan oleh cara/jalannya $\mathrm{p}$ proses penjenuhan ruangan gas di atas liquid, dalam hal tersebut harganya adalah:

$$
\mathrm{y}=\frac{\mathrm{nR}_{\mathrm{vap}} \mathrm{T}}{\mathrm{W}}
$$

$\mathrm{n}=$ koefisien penguapan

$\mathrm{w}=$ kecepatan linier rata-rata penurunan permukaan produk dalam tank pada saat perpompaan $(\mathrm{m} / \mathrm{jam})$ 


$$
\begin{aligned}
\mathrm{R}_{\mathrm{vap}}= & \text { konstanta gas di atas } \\
& \begin{array}{l}
\text { permukaan liquid }(\mathrm{kgm} / \mathrm{mg} \\
\text { derajat })
\end{array} \\
\mathrm{T}= & \text { temperatur gas di atas } \\
& \text { liquid }(\mathrm{K})
\end{aligned}
$$

\section{METODOLOGI PENELITIAN}

\subsection{Teknik Analisis Data}

Evaporation loss floating roof tanks terdiri dari :

a. Standing storage tank loss

Losses dimana tanki dalam keadaan diam atau level tanki tetap (ullage tetap).

b. Withdrawal loss

Losses dimana saat isi tanki ditarik atau dikurangi.

\subsection{Pengolahan Data}

a. Standing storage loss

Variable perhitungan:

a) Seal-related factor

b) Wind speed factor

c) Vapor pressure function

d) Vapor molecular weight

e) Product factor.

f) Density of condensed vapor

g) Seal-related factor: Ks dan n (welded tanks dan rivated tanks)

$\mathrm{Ks}=$ average seal factor

$\mathrm{n}=$ wind speed exponent $\left(\mathrm{V}^{\mathrm{n}}\right)$

Wind Speed Factor, $\mathrm{V}^{\mathrm{n}}$ dapat ditentukan:

1. Dapat dihitung atau dibaca langsung dari grafik dengan mengetahui kecepatan angin dan exponent kecepatan angin dari tabel.

2. Kecepatan angin rata-rata: 2 s.d. 15 miles/jam.

3. Bila tdk tersedia, boleh gunakan data rata-rata kecepatan angin negara terdekat.

Vapor Pressure Function $\left(\mathrm{P}^{*}\right)$ dapat ditentukan:

1. Dapat dihitung berdasarkan rumus $\mathrm{P}^{*}=\ldots$ (dalam grafik)

2. Dapat dibaca langsung dari grafik dengan diketahui besarnya vapor pressure $(\mathrm{P})$ dalam psia. Vapor pressure (P) gasoline/naphtha dan crude oil dapat ditentukan dengan menggunakan grafik hubungan RVP, slope dan temperatur storage (Ts).

3. Apabila Ts tidak diketahui, boleh menggunakan ketentuan pada tabel sesuai warna tanki.

Vapor Molecular Weight (BM Uap) dapat ditentukan:

1. Berat molekul uap (Mv) dpt dihitung berdasarkan komposisi $\mathrm{HC}$.

2. Bila tidak diketahui, boleh diasumsikan nilainya $64 \mathrm{lb} / \mathrm{lb}$.mol utk gasoline dan 50 lb/lb.mol utk crude oil.

Product factor $(\mathrm{Kc})$ dapat ditentukan:

Product factor $(\mathrm{Kc})$ hanya dibedakan antara refinery stocks sebagai gasoline / naphtha dan crude oil. Untuk refinery stocks $\mathrm{Kc}=$ 1,0. Untuk crude oil $\mathrm{Kc}=0,4$.

Density of Condensed Vapor

Density of condensed vapor $\left(\mathrm{W}_{\mathrm{v}}\right)$ tidak diketahui, maka dapat diperkirakan dengan menggunakan hubungan antara $\mathrm{W}_{\mathrm{v}}$ dan $\mathrm{Mv}$ (BM uap) sebagai berikut:

$$
\begin{gathered}
\mathrm{W}_{\mathrm{v}}=0,08 \cdot \mathrm{M}_{\mathrm{v}} \\
\mathrm{Ls}=\mathrm{Ks} \cdot \mathrm{V}^{\mathrm{n}} \cdot \mathrm{P}^{*} \cdot \mathrm{D} \cdot \mathrm{Mv} \cdot \mathrm{Kc}
\end{gathered}
$$

Dimana: $\quad$ Ls $=$ standing loss (lb/year)

$\mathrm{Ks}=$ seal factor (lihat tabel)

$\mathrm{V}^{\mathrm{n}}=$ kecepatan angin $(\mathrm{mph})$ (lihat grafik)

$\mathrm{n}=$ seal related wind speed exponent (lihat tabel)

$\mathrm{P}^{*}=$ vapor pressure function (lihat grafik)

$\mathrm{D}=\operatorname{diameter}(\mathrm{ft})$

$\mathrm{Mv}=$ berat molekul rata-rata vapor $(\mathrm{lb} / \mathrm{mol})$

$\mathrm{Kc}=$ product factor misal, crude oil $\mathrm{Kc}=0,4$ gasoline $\mathrm{Kc}=1$

Untuk condensed vapor $=\frac{\mathrm{Ls}(\mathrm{lb} / \mathrm{year})}{42(\mathrm{Wv})}$

Dimana: $\mathrm{Wv}=$ density of condensed vapor (lb/gal)

Untuk gasoline $\mathrm{Wv}=0,08 \mathrm{Mv}$ 
b. Withdrawal loss

Perhitungan menggunakan:

$$
\mathrm{Lw}=\frac{0,943 \mathrm{xCxW}_{1}}{\mathrm{D}}
$$

Dimana : $\mathrm{Lw}=\mathrm{lb} /$ year

$$
\begin{aligned}
& \mathrm{LW}= \mathrm{b} / \mathrm{year} \\
& \mathrm{Lw}(\mathrm{bbl} / \text { year })=\frac{\mathrm{Lw}(\mathrm{lb} / \mathrm{year})}{\mathrm{D}} \\
& \mathrm{Q}=\begin{array}{l}
\text { average throughput } \\
\text { (bbl/year) }
\end{array} \\
& \mathrm{C}=\begin{array}{ll}
\text { shell clingage factor } \\
\text { (lihat tabel) }
\end{array} \\
& \mathrm{W}_{1}=\text { densitas cairan (lb/gal) }
\end{aligned}
$$

Jika tidak ada data untuk gasoline, maka gunakan $\mathrm{W}_{1}=6,1 \mathrm{lb} /$ gallon .

\section{HASIL DAN PEMBAHASAN}

\subsection{Perhitungan Evaporation Loss pada Floating Roof Tanks}

Berikut data yaang diperoleh dari penelitian yang dilakukan:

a. Jenis tanki $=$ Floating roof tank, welded, good condition, mechanical Shoe Primary Seal.

b. Digunakan untuk pengisian

c. Diameter tank (D) $=100 \mathrm{ft}$

d. Bahan cat $=$ Alumunium Color

e. Reid vapour pressure (RVP)

f. Density $\left(\mathrm{W}_{\mathrm{L}}\right)=6,1 \mathrm{lb} /$ gallon

g. Throughput $(\mathrm{Q})=1.500 .000 \mathrm{bbl} /$ year

h. Suhu rata-rata $(\mathrm{Ta})=60^{\circ} \mathrm{F}$

i. $\quad$ Kecepatan angin $(\mathrm{V})=10 \mathrm{mph}$

j. Tekanan Atmosfir $(\mathrm{P})=14,7 \mathrm{psia}$

Penentuan losses menggunakan

persamaan berikut:

\subsubsection{Standing Storage Loss}

Penentuan standing storage loss menggunakan persamaan berikut:

$$
\mathrm{Ls}=\mathrm{Ks} \cdot \mathrm{V}^{\mathrm{n}} \cdot \mathrm{P}^{*} \cdot \mathrm{D} \cdot \mathrm{Mv} \cdot \mathrm{Kc}
$$

Dengan menggunakan Table 1: Summary of Aveage Seal Factors $(K s)$ and Wind Speed Exponents. API Publication 2517, maka akan diperoleh data sebagai berikut:
a. Average seal factor $\left(\mathrm{K}_{\mathrm{s}}\right)=1,2$
b. Wind speed exponents $(\mathrm{n})=1,5$
c. Wind speed / kecepatan angin $(\mathrm{V})=10$ $\mathrm{mph}$
d. Wind speed factor (Vn) = 32 (Fig.1. API Publication .2517). Dengan menggunkan Table-2 Average Annual

Stock Storage Temprature (Ts) as a Function of Paint Tank Color - API Publication 2517, maka didapatkan untuk cat alumunium:

$$
\begin{aligned}
& \mathrm{Ts}=\mathrm{Ta}+2,5^{\circ} \mathrm{F} \\
& \mathrm{Ts}=60^{\circ} \mathrm{F}+2,5^{\circ} \mathrm{F} \\
& \mathrm{Ts}=62,5^{\circ} \mathrm{F}
\end{aligned}
$$

Dengan menggunakan Fig.3 True Vapor Pressure $(P)$ of Refined Petroleum Stocks (1 psi to 20 psi RVP) API Publication 2517:

$$
\begin{aligned}
& \mathrm{Ts}=62,5^{\circ} \mathrm{F} \\
& \mathrm{RVP}=10 \mathrm{psi}
\end{aligned}
$$

Slope untuk gasoline $=3$

Diperoleh stock true vapour pressure $(\mathrm{P})=5,4$ psia. Kemudian dilakukan penentuan vapour pressure function $\left(P^{*}\right)$.

$$
\mathrm{P}^{*}=\left[\frac{\frac{\mathrm{P}}{14,7 \mathrm{psia}}}{\left\{1+\left(1-\frac{\mathrm{P}}{14,7 \mathrm{psia}}\right)^{0,5}\right\}^{2}}\right]
$$

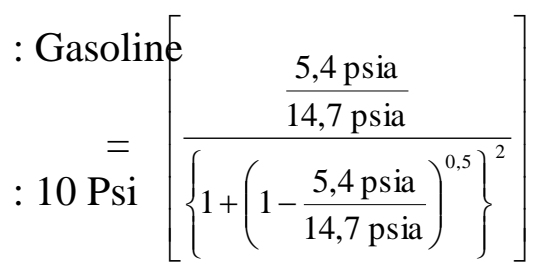

$\mathrm{P}^{*} \quad=0,114 \mathrm{psia}$

$$
\text { Untuk gasoline : }
$$

a. Product factor $\left(\mathrm{K}_{\mathrm{c}}\right)=1$

b. $\mathrm{Kc}=0,4$ (crude oil)

c. Berat molekul rata-rata vapour $(\mathrm{Mv})$ gasoline $=64 \mathrm{lb} / \mathrm{mol}$

d. Density of condensated vapour (Wv)

$$
\begin{aligned}
\mathrm{Wv} & =0,08 . \mathrm{Mv} \\
& =0,08 \times 64 \mathrm{lb} / \mathrm{mol} \\
\mathrm{Wv} & =5,1 \mathrm{lb} / \mathrm{mol}
\end{aligned}
$$
loss (Ls):

Sehingga didapatkan standing storage

$$
\begin{aligned}
\mathrm{Ls} & =\mathrm{Ks} \cdot \mathrm{V}^{\mathrm{n}} \cdot \mathrm{P}^{*} \cdot \mathrm{D} \cdot \mathrm{Mv} \cdot \mathrm{Kc} \\
\mathrm{Ls} & =(1,2) \cdot(32) \cdot(0,114) \cdot(100) \cdot(64) \cdot(1) \\
\mathrm{Ls} & =28 \cdot 016,6 \mathrm{lb} / \text { year } \\
\mathrm{Ls} & =\frac{28 \cdot 016,6 \mathrm{lb} / \text { year }}{(42) \times(\mathrm{Wv})} \mathrm{bbl} / \text { year }
\end{aligned}
$$


$\mathrm{Ls}=\frac{28.016,6 \mathrm{lb} / \text { year }}{42 \times 5,1 \mathrm{lb} / \mathrm{mol}}$

$\mathrm{Ls}=131 \mathrm{bbl} /$ year

Jadi, standing storage loss sebesar 131 bbl/year.

\subsubsection{Withdrawal Loss (Lw)}

Penentuan withdrawal loss menggunakan persamaan berikut:

$$
\mathrm{Lw}=0,943 \times \frac{\mathrm{Q} \times \mathrm{C} \times \mathrm{W}_{\mathrm{L}}}{\mathrm{D}}
$$

a. $\quad$ Throughput $(\mathrm{Q})=1.500 .000 \mathrm{bbl} / \mathrm{year}$ Dengan menggunakan Table-3 : Average Clingage Factor (C) bbl/1000 $\mathrm{ft}^{2}$ - API Publication 2517

b. Untuk gasoline average clingage factors $(\mathrm{C})=0,0015 \mathrm{bbl} / \mathrm{ft}^{2}$

c. Density $\left(\mathrm{W}_{\mathrm{L}}\right)=6,1 \mathrm{lb} / \mathrm{gal}$

d. Diameter tanki $(\mathrm{D})=100 \mathrm{ft}$

$\mathrm{LW}=\frac{0,943 \mathrm{ft}^{3} \mathrm{gal} / / \mathrm{bl}^{2} \times 1.500 .000 \mathrm{lb} / \mathrm{year} \times 0,0015 \times 6,1 \mathrm{lb} / \mathrm{gal}}{100 \mathrm{ft}}$

$=129 \mathrm{lb} /$ year

$=\frac{129 \mathrm{lb} / \mathrm{yaer}}{(42)(5,1 \mathrm{lb} / \mathrm{mol})}$

$=0,6 \mathrm{bbl} /$ year Jadi, withdrawal loss sebesar 0,6 bbl/year.

Dengan demikian sehingga didapatkan evaporation loss (Le)

$$
\mathrm{Le}=\mathrm{Ls}+\mathrm{Lw}
$$

Le $=131 \mathrm{bbl} /$ year $+0,6 \mathrm{bbl} /$ year

$=131,6 \mathrm{bbl} /$ year

Jadi, evaporation loss floating roof tanks sebesar 131,6 bbl/year.

\subsection{Pembahasan}

Dari perhitungan penyusutan yang telah dilakukan pada tanki penampung jenis floating roof dengan jenis produk yang ditampung adalah gasoline dapat kita lihat bahwa losses yang disebabkan saat tanki dalam keadaan diam atau level tanki tetap (ullage tetap) (standing storage tank loss) yaitu sebesar $131 \mathrm{bbl} /$ year yang setara dengan 20.829 liter/tahun. Sedangkan losses pada saat isi tanki ditarik atau dikurangi withdrawal loss sebesar 0,6 bbl/year setara dengan 95,4 liter/tahun. Dengan demikian total seluruh losses tiap tahun yaitu sebesar 131,6 bbl/year setara dengan 20.924,4 liter per tahun sehingga apabila harga gasoline rata-rata Rp. 9.900 /liter kerugian yang ditanggung sebesar Rp. 207.151.560 per tahun.

\section{KESIMPULAN}

Semakin besar ullage, maka semakin berpotensi terjadinya losses, karena sifat gas sendiri mempunyai sifat mengisi ruang kosong. Losses juga dipengaruhi oleh kondisi lingkungan yaitu Temperatur dan kecepatan angin. Dimana semakin tinggi temperatur maka fraksi ringan akan mengalami penguapan / molekul-molekul zat keluar dari liquid sedangkan kecepatan angin identik dengan memperbesar volume yang sangat berpengaruh terjadinya evaporasi. Sifat fisik suatu gas juga mempengaruhi unsur pembentuk uap (vapour pressure/RVP) karena semakin besar tekanan uap maka semakin besar pula potensi losses. Losses Uap itu sendiri tidak bisa dihindari namun bisa dikendalikan.

\section{DAFTAR PUSTAKA}

1980. Tanks, Second Edition. Washington DC.

American Petroleum Institute. 1962. Evaporation Loss from Fixed Roof Tanks. New York.

Muchtisar D.P. 1982. Oil Losses dalam Transportasi dan Penyimpanan. Cepu: PPTMG LEMIGAS.

Nurhadi, Indra. 1991. Tank and Vessels, Bimbingan Profesi Sarjana Teknik (BPST) Angkatan XIV. Jakarta: Direktorat Pengolahan.

Sutjiatmo, Bambang 1991. Storage Tank, Bimbingan Profesi Sarjana Teknik (BPST) Angkatan XIV. Jakarta: Direktorat Pengolahan.

Walas, M.S., Chemical Process Equipment Selection and Design. Butterworth 